\title{
1992 MRS Fall Meeting Extends Boundaries of Materials Science
}

Research presented at the 1992 MRS Fall Meeting, held in Boston, Massachusetts, November 30-December 4, further expanded the boundaries of materials science, pushing time and size scales to their limits and suggesting new and refined materials for applications ranging from lithium-based batteries and DRAMs to targeted drug delivery and flat panel displays. The meeting, chaired by Carl C. Koch, North Carolina State University, Stephen J. Pennycook, Oak Ridge National Laboratory, and Alice E. White, AT\&T Bell Laboratories, drew about 4,000 people from around the world.

The ever-expanding array of characterization techniques, which zoom down to the atomic level and capture materials in action, revealed the motion of atoms on surfaces and the evolution of surface and thin-film microstructure. Panel discussions woven into the meeting provided opportunities for gaining broad perspectives on surface diffusion, chemical vapor deposition, interface roughness, and misfit accommodation, using an assortment of analytical methods.

Computational techniques, from electronic structure calculations using first principles to simple applications using geometrical or statistical models, have been expanded to handle more complex interactions and larger collections of atoms, aiming to meet the challenge of modeling real materials. At the same time, materials are shrinking to the nano-regime-fabricated into quantum dots, nanocomposites, and surface-dominated structures-revealing interesting optical, electrical, chemical, and mechanical properties.

Time domains of spectroscopies have been reduced to capture subpicosecond reactions of explosives, while nuclear waste management crowds the opposite limit, seeking answers to materials behavior many millenia into the future.

Laser beams continued to dazzle, with their capabilities for forming, investigating, and processing superconductors, semiconductors, ferroelectrics, metals, polyimides, and diamondlike films.
While there is still much to learn about the fundamentals of fullerene and cuprate superconductivity, development for device applications of the cuprates is forging ahead. For example, long-wire lengths of
Bi-based cuprates imbedded in a Ag matrix and superconducting field effect transistors using a $\mathrm{YBa}_{2} \mathrm{Cu}_{3} \mathrm{O}_{7} / \mathrm{SrTiO}_{3} / \mathrm{Au}$ structure are being developed.

Researchers showed how chemistry and ordering can be used to alter sensing surfaces, conductive polymers, zeolite surfaces, and other materials by design, no longer relying only on what is offered by nature. Then there were those who found that nuts, silk, shells, and other biomolecular materials have lessons to teach, possibly worth duplicating or perhaps useful in a modified form. Genetic engineering has led to cell-specific targeting of molecules for drug delivery and biocompatible peptides that prevent post-operative surgical adhesions.

A novel rechargeable $\mathrm{Li}_{1+x} \mathrm{Mn}_{2} \mathrm{O}_{4} / \mathrm{C}$ bat-

\section{- Turnbull Lectureship.}

Thomas Anthony, General Electric Research and Development Center, received the first Turnbull Lectureship award, recognizing the career of a scientist who has made outstanding contributions to the understanding of phenomena through research, writing, and lecturing, as exemplified by David Turnbull. As part of the award, Anthony gave a lecture at the Fall Meeting. His talk, titled "Understanding Materials with Elemental Physical Models and Simple Experiments," began by honoring David Turnbull's life and his meth ods, then finished by describing his own work.

Turnbull's approach to

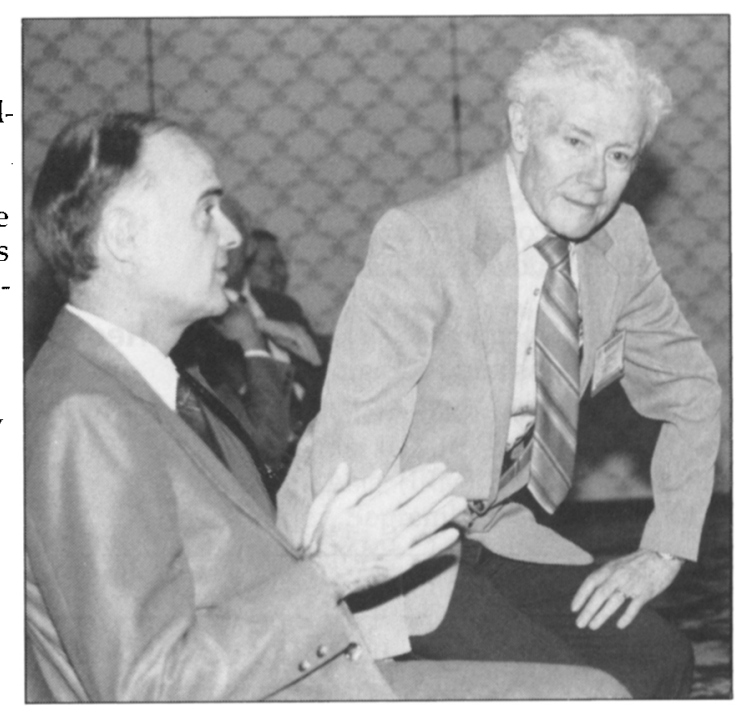
solving problems, Anthony

said, is to (1) think deeply about the problem at the atomic level, (2) create a clean physical model, and (3) conceive of simple experiments to test that model. Anthony then described a handful of his own "Turnbull-like" experiments. For example, while Anthony was a student of Turnbull's at Harvard, they examined fast diffusion of $\mathrm{Au}$ in $\mathrm{Pb}$. Au diffused faster in $\mathrm{Pb}$ than expected for substitutional diffusion-the mechanism expected, based on relative solute size. Indirect evidence indicated it must actually be interstitial diffusion, but the two scientists sought direct evidence. Their experiment involved putting the material in a high-speed centrifuge. Since Au is lighter than $\mathrm{Pb}$, if the Au were substitutional, it would be forced up the gravitational field. If interstitial, it would not have to displace the $\mathrm{Pb}$, so it would go down the field. The result was that the Au was thrown out to the periphery and, after calculating back using thermodynamics, they were able to show that the Au was entirely interstitial in Pb.

Anthony, as Turnbull Lecturer, will be available to give lectures for MRS chapters and sections throughout the year.

For more information, contact John B. Ballance, Executive Director, Materials Research Society, 9800 McKnight Road, Pittsburgh, PA 15237; telephone, (412) 367-3003. 
tery showed a long cycle life and high energy and power density. Also, tiny batteries that can be integrated with computer chips showed potential for biosensors, where the small size of the device is important.

- Plenary Address. John A. Armstrong, IBM vice president of science and technology, discussed issues that research institutions face today, examining the rationale for research funding and the "societal return." His plenary talk is published in this issue's Material Matters column.

w Von Hippel Award. The Von Hippel Award presentation, given by Michael F. Ashby, University of Cambridge, covered a formal method for choosing materials for specific applications using materials selection charts along with performance indices. The selection charts compress material data into a compact, visual, and accessible form. The indices capture performancemaximizing aspects of material behavior for a given application. Charts and indices, together, point toward the optimum materials. Ashby's presentation will appear in a future issue of the MRS Bulletin.

- MRS Medalists. The MRS Medalists presented special invited talks on the innovative achievements for which they received their awards. L. Eric Cross, Pennsylvania State University, spoke about "Relaxor Ferroelectrics; SelfAssembling Nanocomposites." Stephen J. Pennycook, Oak Ridge National Laboratory, spoke on "Direct Atomic Imaging of Materials By Z-Contrast STEM."

- Education Session. Nearly 100 people attended a session to learn about science education needs and to discover ways that technical professionals can get involved. Part of an evening poster session complemented the oral session, with posters displaying K-12 science activities. The session was chaired by Ken Eckelmyer, Sandia National Laboratories and Finley Shapiro, Drexel University. Sandra Spooner, Assistant Superintendent for Curriculum, Cambridge Public Schools, discussed the constraints and the needs of science teachers. Rob Sorenson, Sandia National Laboratories, showed how scientists and engineers can be effective in science education enrichment. He demonstrated how to make "slime" and described other fun experiments that excite K-12 students.

- Society-Wide Colloquium. The first Society-Wide Colloquium was held to discuss national materials policy in an era of globalization of science and technology. Rustum Roy of Pennsylvania State University organized the afternoon session. He was joined by panelists from the United Kingdom (Peter Hirsch), Germany (Günter Petzow), and India (V.S. Arunacha- lam). These countries have a variety of levels of materials policy, although Arunachalam pointed out that India's priorities are completely different from those of the other three countries. Fifty years ago, India had no materials industry to speak of, he said. Since then, they have been working to become equals.

- Technical Sessions. For highlights of the symposia, read the summaries that follow. More detailed information is available on many of the symposia in the published proceedings.

\section{Superconductivity Featured in Discussion of Fullerene Materials}

The range of subjects covered in Symposium AA, Science and Technology of Fullerene Materials, reflected the broad interest in these new classes of materialsfrom organic chemistry to solid-state physics. A major topic was the superconductivity of doped $C_{60}$ (including a joint session with Symposium H, Superconductivity: Materials and Properties). The presentations were more in-depth than in the past, and dealt mainly with the structure and mechanism of the superconductivity. Work on single crystals and quality thin films showed that well-defined structures should be the best way to obtain exact values for many of the parameters, some of which remain controversial. The novel alkali-earth-doped $C_{6}$ superconductors, which demonstrate that the superconductivity of $C_{(i)}$ is not limited to the alkali doped fcc $M_{3} C_{60}$ series, should encourage further search for novel $C_{6 \mid\}}$ superconductors.
Several speakers described their experiments on endohedral fullerenes, i.e., fullerenes containing one or more metal atoms which are detected by mass spectroscopy and ESR. In their efforts to isolate the endohedrals, however, unusual behavior was observed and the characteristic ESR signals disappeared. The possibility that the metals might be found both on the inside and the outside of the fullerenes was clearly suggested.

The transformation of $\mathrm{C}_{610}$ (but not $\mathrm{C}_{70}$ ) to diamond under high pressure and the

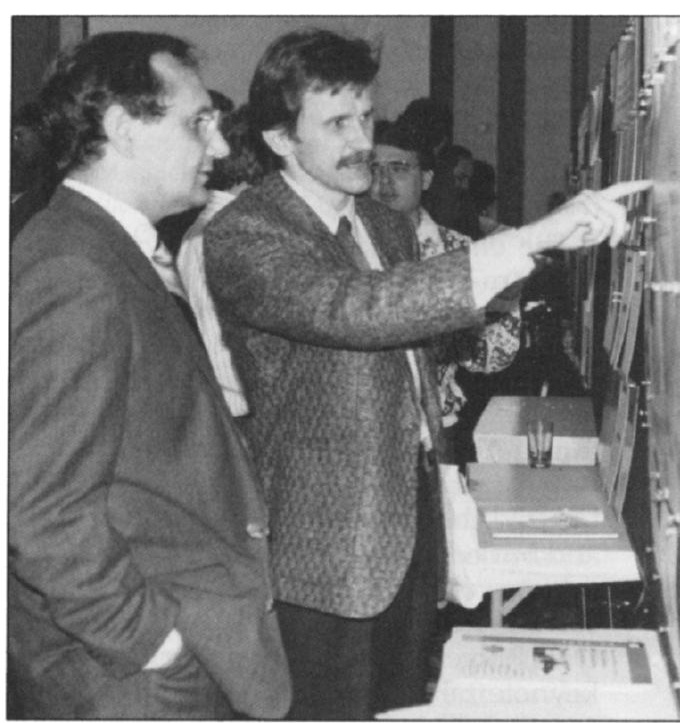

Meeting attendees swap research results at one of four evening poster sessions.

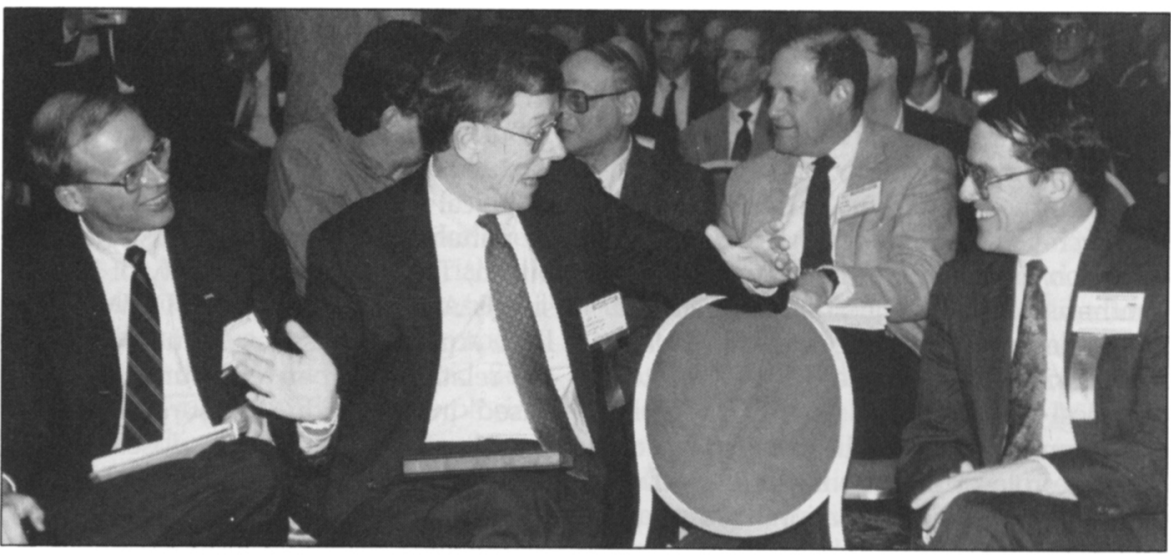

Plenary speaker John A. Armstrong (center), IBM vice president of science and technology, talks to 1991 MRS President, Jim Roberto (right) and 1992 MRS President, Slade Cargill, before his presentation on "Research and Competitiveness: Problems of a New Rationale." (See Material Matters in this issue for Armstrong's full address.) 
broad luminescence of $C_{60}$ confined in onedimensional channels also generated a lot of interest.

The functionalization of $\mathrm{C}_{60}$ through synthesis has made significant progress and should lead the way to a broad class of novel fullerene materials. Novel structures such as carbon nanotubes was the subject of experimental talks on growth mechanism and structure, and many theoretical talks predicted a variety of interesting properties. Clearly these properties will be soon verified, since the corridor talks revealed that a large number of groups are reproducing the large-scale synthesis of nanotubes and are beginning to measure their properties.

\section{Synthesis and Processing \\ Discussed in Session on \\ Beam-Solid Interactions \\ (See MRS Proceedings Vol. 279)}

The emphasis this year in Symposium A, Beam-Solid Interactions: Fundamentals \& Applications, was on fundamentals and applications in key topics such as computer simulations; high-energy beams; radiation damage in metals, semiconductors, and ceramics; amorphization and recrystallization; ion beam mixing; finely focused beams; laser-solid interactions; and buried layers and mesotaxy.

Noteworthy presentations were made in each of the key areas. M. T. Robinson of Oak Ridge National Laboratory gave the keynote talk on computer simulations of atomic collision processes in solids, while J. P. Biersack, Hahn-Meitner-Institut für Kernforschung, discussed Monte Carlo simulations. A. Dunlop, DEA/Ecole Polytechnique, reviewed damage generation by electronic excitations in metals, and $P$. Ehrhart, IFF, examined the particle irradiation generation of point defects in semiconductors. Several authors, including $\mathrm{J}$. R. Conrad, University of Wisconsin, and N.W. Cheung, UC-Berkeley, reviewed the new ion implantation technologies that have emerged from the plasma physics community. J. J. Cuomo, IBM T. J. Watson Research Center, gave an exciting presentation on energetic condensation and the synthesis of amorphous diamond. In the area of laser surface processing, L. L. Kolodziejski, MIT, discussed photo-assisted chemical beam epitaxy, and T. R. Jervis, Los Alamos National Laboratory, examined the role of excimer lasers in surface processing and modification. S.S. Lau, UC-San Diego, gave a presentation on ion beam mixing in semiconductor superlattices. The session on finely focused beams was highlighted with presentations on ion beam lithography at $10 \mathrm{~nm}$ dimensions by R. L. Kubena, Hughes Research Laborato- ries, and on low-energy focused beam processing by K. Gamo, Osaka University, and by a presentation on the process of focused ion beam induced deposition by A. V. Wagner, Harvard University.

\section{Panelists Discuss Surface Morphology and Microstructure (See MRS Proceedings Vol. 280)}

Symposium B, Evolution of Surface and Thin-Film Microstructure, was a forum for the scientific issues central to crystal-vapor interfaces and vapor phase crystal growth. A wide spectrum of topics as well as a wide variety of intellectual approaches to microstructural evolution, ranging from atomistic to continuum investigations, were discussed. Plenary speaker Alex Chernov, Russian Academy of Sciences, set the tone for the symposium in a survey of phenomena that affect the kinetics and thermodynamics of vapor phase crystal growth.

A prominent and programmatically novel feature of the symposium was the series of four panel discussions that provided broad perspectives on critical issues in surface diffusion, kinetics of chemical vapor deposition, interface roughness and structure, and misfit accommodation at strained interfaces. Surface diffusion panelists P. J. Feibelman, Sandia National Laboratories; G. H. Gilmer, AT\&T; B. H. Cooper, Cornell University; and Y. W. Mo, IBM, provided theoretical and experimental perspectives on issues related to surface migration kinetics. Key points that arose in the discussion include the notions that (1) for metal surfaces, hopping of single atoms is not the unique and indeed possibly not the typical mode of surface migration, and (2) for silicon, atomic exchange between near-surface layers may be considerably faster than bulk diffusive exchanges, and (3) scanning tunneling microscope experiments can provide a rich variety of experimental data about the processes that comprise surface diffusion.

Surface chemical reaction processes and film morphological development during chemical vapor deposition were discussed by panelists J. F. Yates, University of Pittsburgh; T. F. Kuech, University of Wisconsin; F. A. Houle, IBM; and D. W. Kisker, IBM. Among the issues discussed were (1) the relationship between surface sciencebased investigations of surface reaction processes performed at low doses and continuous, steady-state film growth by chemical vapor deposition, and (2) the common and distinct features in morphological development during chemical vapor deposition and physical vapor deposition by, e.g., molecular beam epitaxy.

Measurement and physical manifestations of interface roughness were ad- dressed using a broad spectrum of experimental methods, including scanning probe microscopies, transmission electron microscopy, photoluminescence, and $\mathrm{x}$-ray scattering, by panelists J. M. Slaughter, University of Arizona; R. S. Williams, UCLA; E. F. Schubert, AT\&T; and A. Ourmazd, AT\&T. Among the noteworthy points that arose in this discussion were that (1) x-ray scattering experiments utilizing nonspecular scattering may yield considerably more information about interface roughness than is presently obtained in specular reflectivity measurements, (2) in order to characterize interface roughness, appropriate distribution functions need to be defined quantitatively and used more widely, particularly in scanning probe microscopy experiments, and (3) photoluminescence provides information about roughness and thickness of optically active thin films, but must be complemented by other techniques to obtain information about roughness over a wide range of length scales. The power of thermodynamic measurements of the development of roughness in rare-gas films were surveyed by D. Goodstein, Caltech. P. I. Cohen, University of Minnesota, described dynamical measurements of surface roughness using reflection highenergy electron diffraction. A. Zangwill, Georgia Institute of Technology, surveyed analytic and Monte Carlo simulation approaches to length scales and scaling at surfaces.

The accommodation of misfit in epitaxial films was discussed by panelists R. F. Bruinsma, UCLA; D.J. Eaglesham, AT\&T; P. W. Voorhees, Northwestern University; and J. Y. Tsao, Sandia National Laboratories. Particular attention was devoted to the formation of coherent islanded structures as a means of misfit accommodation, and as an interesting morphological instability in strained thin films. Experimental examples of these structures were given for Ge on Si (001), and theoretical approaches to the kinetics of island formation that yield testable, predictive information were discussed. It was also noted that the principle technological interest in island formation centers on its avoidance, and other modes of misfit accommodation by interface defects and substrate deformation were also considered. Models and experimental results for island formation in the InGaAs/ GaAs system were also presented by B. G. Orr, University of Michigan. C. V. Thompson, MIT, outlined the concept of epitaxial grain growth, and described examples of this phenomenon in which strain energy minimization plays a crucial role in the development of epitaxial orientation. 


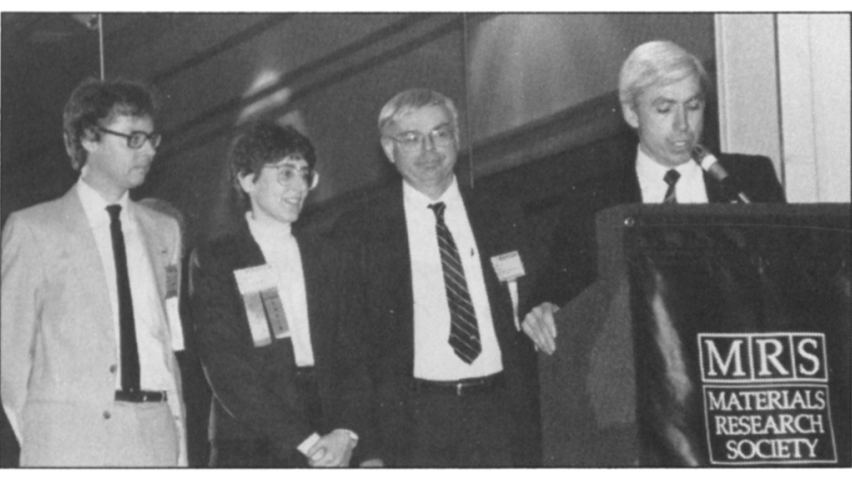

1993 MRS President Tom Picraux (right) offers congratulatory remarks to 1992 Fall Meeting Chairs (from left to right), Stephen Pennycook, Alice White, and Carl Koch.

\section{Morphological Stability of Two-Phase Microstructures Examined}

Three areas of microstructural stability were emphasized during Symposium C, Stability of Microstructures. The first day examined the morphological stability of two-phase microstructures during coarsening or Ostwald ripening. Invited talks considered the role of interfacial microstructure, various global constraints and elastic stress on particle shape changes, and the development of spatial correlations between particles and coarsening rates. Both two- and three-dimensional computer simulations showed that misfit strains associated with second-phase particles can lead to symmetry-breaking particle-shape transitions and significant particle migrations. In addition, misfit strains seem to decrease the coarsening rate and lead to a stabilization of the microstructure. Microstructures coarsening under the influence of stress do not exhibit the same scaling laws as predicted by the Lifshitz and Slyozov and Wagner theories.

A second area of emphasis was grainboundary controlled instabilities. Topics included boundary mobility effects, electromigration, grain boundary selection, the morphological stability of various polycrystalline films, computer simulations, and the stability of boundary regions and intergranular phases in polycrystalline ceramics.

Finally, microstructural instabilities induced by external forces and in thin films were examined. Externally-applied elastic stresses were shown to strongly influence microstructural evolution in two-phase systems while substrate-induced elastic strain affected the morphological stability

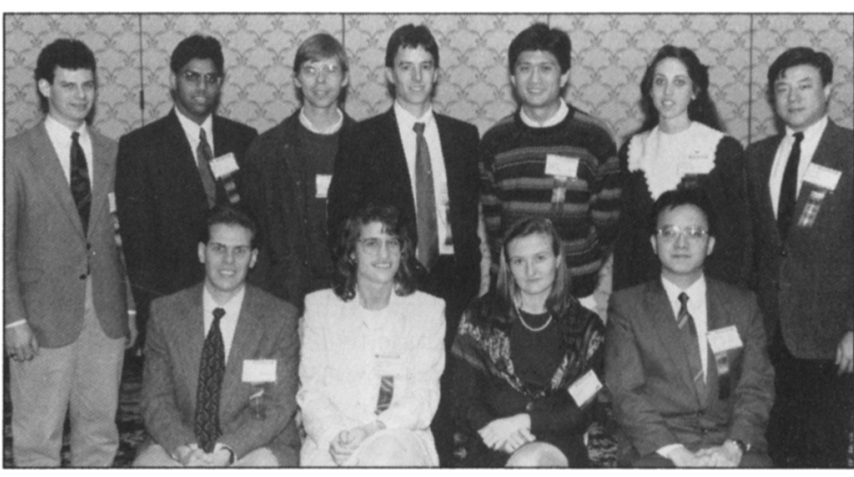

Graduate Student Award Winners at the 1992 MRS Fall Meeting. Front row, left to right: Lance D. Cooley, University of Wisconsin; Chrysanthe D. Terwilliger, Massachusetts Institute of Technology; Catherine Heremans, Massachusetts Institute of Technology; Chengheng R. Kan, University of Wisconsin. Second row, left to right: Nicholas Camillone III, Princeton University; Ashwin K. Ballal, University of Maryland; Joel Mesot, ETH Zurich and Paul Scherrer Institut; John A. Rogers, Massachusetts Institute of Technology; William M. Tong, University of California-Los Angeles; Shelli R. Letellier, University of Washington; Y.Z. Chu, Columbia University. Not pictured: Qing Zhu, University of Pennsylvania. of epitaxial thin films. Likewise, imposed gradients in an electric field or oxygen chemical potential could induce morphological instabilities at solid interfaces and surfaces. These instabilities were observed both experimentally and predicted theoretically.

\section{Compound Semiconductor Growth Focuses on Metalorganic Techniques} (See MRS Proceedings Vol. 282)

The sessions on compound semiconductor growth focused on areas of prime importance for the epitaxial growth techniques of current significant interestmetalorganic chemical vapor deposition (MOCVD) and metalorganic molecular beam epitaxy (MOMBE). Those areas included selective area growth (SAG), alternative precursors (novel sources), in-situ diagnostics, and dopant incorporation. Understanding SAG is significant for device fabrication and optoelectronic integration.

During Symposium E, Chemical Perspectives of Microelectronic Materials III, G. J. Davies of BT Laboratories presented mechanistic studies of the SAG process and elucidated the role of arsenic flux. There are several motivations for exploring the use of alternative precursors: lower growth temperatures, improved process safety, efficient utilization of the source, and layer purity and uniformity. R. M. Biefeld of Sandia National Laboratories examined the use of alternative antimony sources for the growth of InSb by MOCVD with a view toward detector applications. W. Rees of Florida State University pre- sented a novel method for nitrogen doping ZnSe by MOCVD, using zinc amides that contain a pre-existing $\mathrm{Zn}-\mathrm{N}$ bond. Alternative arsenic and phosphorus precursors (bisphosphinoethane, tertiarybutylphosphine, tertiarybutylarsine, dimethylaminoarsine, and dimethylaminophosphine) for MOMBE were discussed by several authors. In the area of dopant incorporation, carbon is of great interest since it can be incorporated at high concentrations $\left(>10^{21}\right.$ $\mathrm{cm}^{-3}$ for GaAs) with low diffusivity, thus enabling fabrication of high-speed devices such as heterojunction bipolar transistors, without incurring device degradation through dopant diffusion. M. Weyers of Ferdinand-Braun-Institut für Höchstfrequenztechnik presented the first theoretical study of the carbon doping behavior in III-Vs.

There was considerable interest in the session on dielectrics. Dielectric materials can be used in a variety of semiconductor device applications, such as etchingmasks, barrier layers, electrical isolation between conductive regions, and threedimensional device structures. Tantalum pentoxide $\left(\mathrm{Ta}_{2} \mathrm{O}_{5}\right)$ is the most extensively developed high dielectric constant metal oxide. H. Treichel of Siemens AG discussed the deposition of $\mathrm{Ta}_{2} \mathrm{O}_{5}$ using several organometallic precursors, the various deposition techniques (plasma-enhanced chemical vapor deposition, hotwall lowpressure chemical vapor deposition, etc.), and the annealing methods. Several characterization techniques were used to examine the optical properties, chemical composition, and structural properties of 
the films. He concluded that $\mathrm{Ta}_{2} \mathrm{O}_{5}$ appears to be the leading candidate for use in the intermediate production technology for advanced Mbit DRAMs.

Other areas of substantial interest included laser microchemical processing of silicon (as discussed by D. J. Ehrlich of MIT), laser-assisted metallization (aluminum, copper, tungsten, and platinum), and the deposition of silicon carbide using novel sources that enable lower growth temperatures.

\section{Electronic and Chemical Properties Influenced by Surfaces and Interfaces \\ (See MRS Proceedings Vol. 283)}

Symposium F, Microcrystalline Semiconductors: Materials Science \& Devices, presented significant progress in the field since a similar symposium was held three years ago.

Microcrystals and nanocrystals form a class of materials that are neither amorphous nor single crystalline. Many of their properties are unusual; for example, the electronic and chemical properties are strongly influenced by the surfaces or interfaces, and quantization affects the electronic states. As a result, micro- and nanocrystalline semiconductors display unique properties that may be exploited in novel devices. Symposium F brought together materials scientists, engineers, device physicists, chemists, and solid state physicists who are active in various areas of growth, characterization, modeling, and device applications of micro- and nanocrystalline semiconductors. As expected, the sometimes spectacular advances reported in the symposium were matched by the new questions raised by these very same advances. It also quickly became apparent that bringing together the three areas mentioned below in the same symposium was productive because the technological and scientific issues faced by these three communities have a lot in common.

Three topics were covered by the symposium. The first area was microcrystalline and polycrystalline silicon film growth and device applications. This constitutes the historical core of the symposium. The sessions were devoted to growth and characterization of microcrystalline silicon, polysilicon, and laser and thermal processing of polysilicon.

The second area was light-emitting porous silicon and related materials. Since the demonstration in 1990 that bright, visible light can be emitted by porous silicon, the field has expanded considerably. The sessions were devoted to fabrication of silicon and germanium nanostructures, characterization of porous silicon, theory of

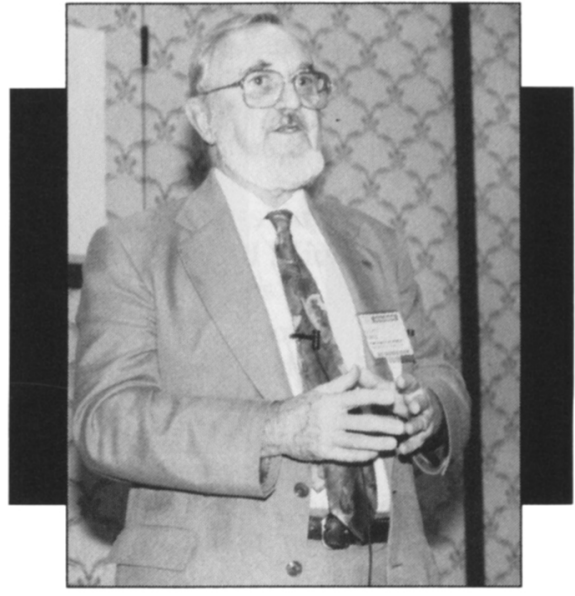

Eric Cross, 1992 MRS Medalist, gives his award lecture on relaxor ferroelectrics.

silicon nanostructures, passivation of porous silicon, and optoelectronic properties and device applications of porous silicon. In addition, the most recent results on porous silicon were presented.

The third area was quantum wires and quantum dots made of III-V and II-VI semiconductors. Major advances have been made in this area since 1989 and some of the most important of them were reported.

\section{Deposition and Characterization of Amorphous Insulators Discussed} (See MRS Proceedings Vol. 284)

Three of the 13 sessions of Symposium G, Amorphous Insulating Thin Films, were devoted to the deposition of amorphous hydrogenated silicon nitride (a$\left.\mathrm{SiN}_{\mathrm{x}}: \mathrm{H}\right)$. Both theoretical and experimental analysis of its structural defects were also presented. Of the various deposition methods used, plasma-enhanced chemical vapor deposition (PECVD) appears to be the most popular. A wide range of characterization techniques including NEXAFS, electron paramagnetic resonance, photoluminescence, and photothermal deflection spectroscopy was covered in the session on experimental defect studies.

The fourth session concerned nonvolatile memory devices based primarily on oxide/nitride structures. State-of-the-art devices can be written in $\mu$ sec and erased in msec, and withstand $\sim 10^{7}$ write/erase cycles before wearout. Research needs to be done to reduce operating voltages.

A series of presentations covered PECVD of amorphous silicon dioxide (a$\mathrm{SiO}_{2}$ ), including the effects of ion energy during the deposition process. It was demonstrated that ion energies $>100 \mathrm{eV}$ could

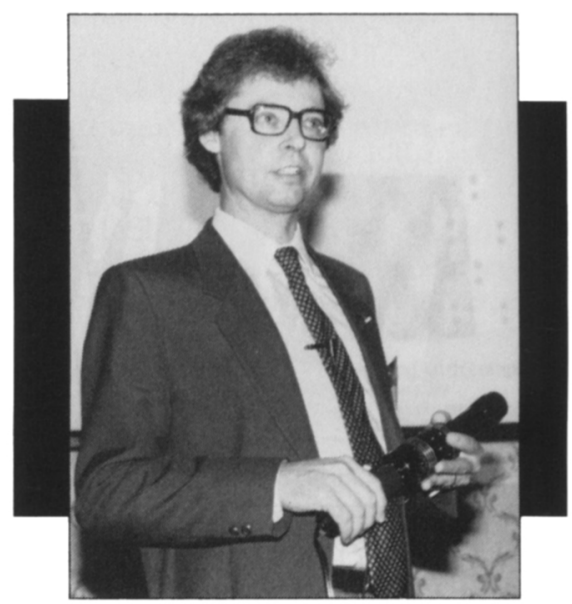

1992 MRS Medalist, Stephen Pennycook, gives his award lecture on direct atomic imaging of materials by Z-contrast STEM

improve the electrical and mechanical integrity of these films. Plasma-assisted dielectric deposition for III-V compound semiconductors was also discussed and demonstrated to be viable.

The role of impact ionization, trap creation, and hydrogen was extensively discussed in the two sessions devoted to degradation and breakdown in $\mathrm{a}^{-} \mathrm{SiO}_{2}$ thin films. It would appear that the importance of hydrogen should not be underestimated in this domain. It was proposed that a solution to etching-induced degradation of a$\mathrm{SiO}_{2}$ might be through the use of neutral beams. However, it was demonstrated that such beams can induce crystallization and macroscopic variations in thermal oxide films.

In the session devoted to thin-film transistors for flat panel display applications, a series of solutions was proposed for the problem of obtaining higher mobility devices with a uniform quality dielectric gate. Variations included anodized Al, a$\mathrm{SiN}_{\mathrm{x}}: \mathrm{H}$, and $\mathrm{a}-\mathrm{SiN} \mathrm{x}: \mathrm{H} / \mathrm{a}-\mathrm{SiO}_{2}$ stacks.

Although thermal $\mathrm{SiO}_{2}$ thin films have been the dominant dielectric for microelectronic applications for many years, there is a growing need for, and hence interest in, developing low-dielectric constant materials for reduced delay in interconnects, and high-dielectric constant materials to minimize the space occupied by storage capacitors (DRAMs). The session devoted to these materials revealed several plausible candidates such as $\mathrm{Ta}_{2} \mathrm{O}_{5}, \mathrm{BaTiO}_{3}$, and lead zirconate titanate for high-dielectric constant materials, and SiBN and sol-gel silicates for low-dielectric constant materials. This field is expected to develop significantly with the future demands put forth by the microelectronics community. 
The final session was essentially devoted to the structure and characterization of buried a- $\mathrm{SiO}_{2}$ layers formed by $\mathrm{O}^{+}$ion implantation. This technique has evolved irito a viable method for producing commercial silicon on insulator substrates for various applications requiring, for example, radiation hardness, high-speed performance, and high-temperature operation. The physical nature of the buried oxide as compared to thermal oxide, however, remains to be clarified

\section{High-Temperature \\ Superconductivity Symposium Includes Session Dedicated to Michael Schluter}

A major topic of Symposium $\mathrm{H}$, Superconductivity-Materials and Properties, was high-temperature superconductivity in the cuprates, but there were also numerous reports about heavy-fermion, organic, and fullerene $\left(\mathrm{C}_{\text {ol1 }}\right)$ superconductivity.

A joint session on superconductivity in doped $C_{n k l}$ was held with Symposium AA, Science and Technology for Fullerene Materials. This session was dedicated to the memory of Michael Schluter, who made important contributions to the theory of fullerene superconductivity before his untimely death on November 18, 1992. The organizers are grateful to his close collaborator, Michel Lannoo, who on short notice generously agreed to travel from Lille, France, to present an invited talk in Schluter's place.

Although there is considerable evidence that the origin of superconductivity in fullerenes is the electron-phonon interaction, a case still can be made for an electronic mechanism. Perhaps the most controversial topic in fullerene superconductivity, however, is the size of the carbon isotope effect, namely the magnitude of the exponent $\alpha$ in the dependence of the transition temperature $\mathrm{T}$, on the carbon atomic mass $M\left(T_{i} \propto M^{-\alpha}\right)$. While for a pure electronphonon mechanism involving a single atomic mass $M$ the value of $\alpha$ should be 0.5 , reported experimental values of $\alpha$ in intercalated $C_{6: 1}$ with different $C$ isotopes range from 0.3 to 1.4 .

Another joint session on pulsed laser ablation of high $T_{t}$ superconductors was held in cooperation with Symposium I, Laser Ablation in Materials Processing: Fundamentals and Applications.

The papers presented in Symposium $\mathrm{H}$ tended to examine the basic science of superconductivity, especially the cuprates, and there were reports on the use of essentially all the tools of materials science, chemistry, and physics for learning about these materials. The key topics of this sym- posium were fundamental theories and properties, the high-frequency response of superconductors, properties of thin films and superlattices, the fabrication of junctions and thin-film devices, flux pinning, critical currents, vortices and flux motion, bulk superconductors, single crystals, and applications.

Significant advances were reported in the development of high-temperature superconductors for both large-scale and device applications. Particularly impressive were the reports of progress toward the fabrication of long lengths of multifilamentary wires and tapes made of bismuthbased cuprate superconductors imbedded in a silver matrix. These conductors have potential for use in low magnetic fields at $77 \mathrm{~K}$ or in high fields at temperatures of 20 $\mathrm{K}$ or $4.2 \mathrm{~K}$.

A. P. Malozemoff reviewed results from American Superconductor Corporation using two approaches, the powder-in-tube method and the metallic precursor method. While the former method is further advanced, the latter shows considerable promise for the fabrication of high-filament-count conductors that are relatively insensitive to tensile strain. $\mathrm{K}$. Togano reviewed progress at the National Research Institute for Metals, Japan, in the preparation of superconducting tapes and their use in the fabrication of small pancake coils. Recently such double-pancake coils have generated magnetic fields of $1.64 \mathrm{~T}$ and $1.25 \mathrm{~T}$ under bias fields of $0 \mathrm{~T}$ and $6 \mathrm{~T}$, respectively, at $4.2 \mathrm{~K}$.

Another striking impression is that significant worldwide progress has been made in the ability to make high-quality thin films of high-temperature superconductors on different kinds of substrates and to pattern these films into various useful devices, including SQUIDs and passive microwave circuit elements. For example, X. X. Xi of the University of Maryland described three-terminal multilayer devices of $\mathrm{YBa}_{2} \mathrm{Cu}_{3} \mathrm{O}_{7} / \mathrm{SrTiO}_{3} / \mathrm{Au}$, in which the transport properties of the $\mathrm{YBa}_{2} \mathrm{Cu}_{3} \mathrm{O}_{7}$ thinfilm superconductor could be strongly modulated by applying a modest voltage to the $\mathrm{Au}$ gate. The resulting device is called a SuFET, a superconducting fieldeffect transistor.

\section{Laser Ablation is Unique Tool for Materials Processing and Formation (See MRS Proceedings Vol. 285)}

Symposium I, Laser Ablation in Materials Processing: Fundamentals and Applications, attracted researchers involved in laser ablation of polyimides, ceramics, high $T_{\text {. superconductors, semiconductors, }}$ ferroelectrics, metals, and diamond-like films. The diverse selection of materials be-

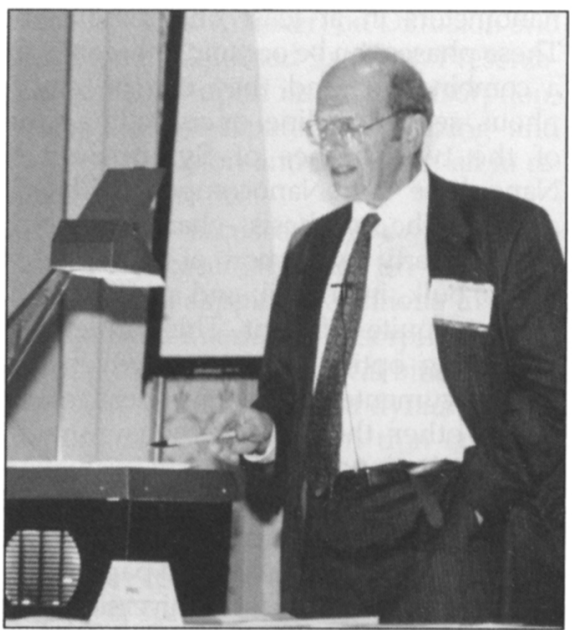

Peter Hirsch, former chaiman of the Atomic Energy Authority in the United Kingdom, addresses policy issues in the Society-Wide Colloquium on "National Materials Policies in the" Era of International Science and Technology."

ing processed by laser ablation illustrates the potential that this technique offers in solid-state physics and materials engineering. In the course of this symposium it became clear, probably more than ever before, that laser ablation is indeed a unique tool for the formation, investigation, and processing of materials.

Laser-induced vacuum deposition of thin films, and fabrication of electronic microstructures by surface modification, etching, and selective area epitaxy were discussed extensively. Advancements made in these areas have enabled atomiclevel growth control and lead to the fabrication of novel structures consisting of high $\mathrm{T}_{\text {c }}$ superconductors, as well as quantum wells and superlattices of semiconductors. Periodic line structures in polymers, with periods ranging from $166 \mathrm{~nm}$ to $950 \mathrm{~nm}$, have been produced with the excimer laser using a holographic technique. With the same holographic technique, a periodic ripple structure with the spacing of 169 $\mathrm{nm}$, and a 200-nm dot array have been demonstrated in $\mathrm{n}-\mathrm{GaAs}$ and $\mathrm{InP}$, respectively. This method for fabrication of semiconductor nanostructures may be useful in the research of quantum confinement effects in structures with reduced dimensions.

\section{Structure of Nanophase and Nanocomposite Materials Leads to Interesting Optical Properties (See MRS Proceedings Vol. 286)}

Nanocomposite materials are composed of nanophases on the order of one to a few 
nanometers in at least one dimension. These phases can be organic, inorganic, or a combination, and they can be amorphous, semicrystalline, or crystalline. One of the two themes of Symposium J, Nanophase and Nanocomposite Materials, was the synthesis, characterization, and property evaluation of nanophases whose bulk, interfacial, and surface structures are quite different. This can lead to interesting optical properties, which has been documented by several investigators.

The other theme was the synthesis, characterization, and property evaluation of different types of nanocomposites such as sol-gel, biological, structural ceramic, dielectric, ferroic, etc. An invited paper by R. Roy of Pennsylvania State University dealt with sol-gel nanocomposites and demonstrated radical improvements in chemical reactivity leading to lower transition and sintering temperatures, and structural reactions (based on solid-state epitaxy). Another invited paper by K. Niihara of Osaka University, described new nanocomposite structural ceramics. Based on the predicted roles of micro- and nanocomposites, he has postulated and demonstrated that it is necessary to hybridize the nanocomposite and microcomposite for designing supertough and strong ceramics, i.e., the nanocomposites reinforced with particles, whiskers, platelets, and long fibers in the micrometer range. He showed that the Sialon/ $\mathrm{SiC}$ nanocomposites reinforced by long fibers gave fracture toughness in the range of $20-30 \mathrm{MPa}^{\cdot} \mathrm{m}^{1 / 2}$ and strength of over $1,000 \mathrm{MPa}$ even at a temperature of $1,500^{\circ} \mathrm{C}$. D.J. Birchall of the University of Keele described many biological nanocomposites from which materials scientists can learn lessons for the design and synthesis of composites.

\section{Silicon Nitride Developments Build on Fundamentals \\ (See MRS Proceedings Vol. 287)}

Symposium K, Silicon Nitride Ceramics: Scientific and Technological Advances, brought together an international group of researchers and engineers to review the progress and new developments in the field. Silicon nitride ceramics have been developed for a number of applications (e.g., automotive turbocharger rotors) and have considerable potential for future advanced energy and propulsion systems. The progression of these materials has been based on advances in the fundamental understanding of processing-phase equilibria-microstructure-mechanical properties relationships coupled with the development of the manufacturing and engineering practice with the capability of producing highly reliable components.
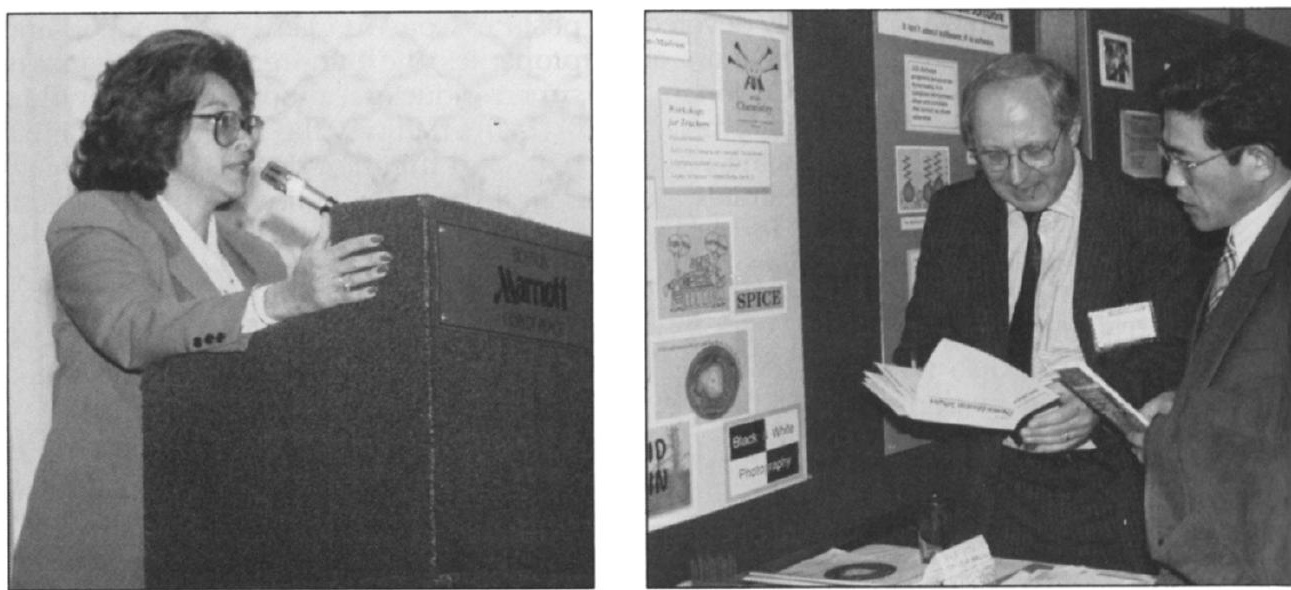

Sandra Spooner, assistant superintendent for curriculum, Cambridge Public Schools, addresses the role scientists can play in enhancing K-12 science education.

Advances in understanding how the microstructure and grain boundary phases evolve and characterizing their influence on various mechanical properties (e.g., toughness, creep) were shown to be critical in the development of silicon nitrides. This required continued efforts to define the phase equilibria in these multi-component, often complex systems. During the symposium, T. Y. Tien of the University of Michigan was recognized for his contributions to these advances.

\section{Technological Properties of Intermetallic Systems Examined (See MRS Proceedings Vol. 288)}

Recent progress in the intermetallics area was summarized during Symposium L, High-Temperature Ordered Intermetallic Alloys - V. In addition to structure, phase stability, and deformation behavior, this symposium also emphasized other properties of technological interest such as creep, fatigue, fracture, toughness, environmental effects, processing, and joining. Intermetallic systems discussed were titanium aluminides, nickel aluminides, iron aluminides, silicides and advanced intermetallics such as beryllides. Several papers demonstrated the effect of the test environment in many intermetallics. The paper by C. L. Fu of Oak Ridge National Laboratory presented calculations of point defects in $\mathrm{NiAl}, \mathrm{FeAl}$, and TiAl. The role of mobile dislocations in controlling room temperature ductility and toughness in $\mathrm{NiAl}$ was demonstrated, through strain aging experiments, by J. E. Hack of Yale University. Creep behavior of NiAl was discussed in an excellent presentation by W. D. Nix of Stanford University. Excellent fatigue behavior of NiAl was discussed in several
Poster session attendees discuss ideas for $\mathrm{K}-12$ science education activities.

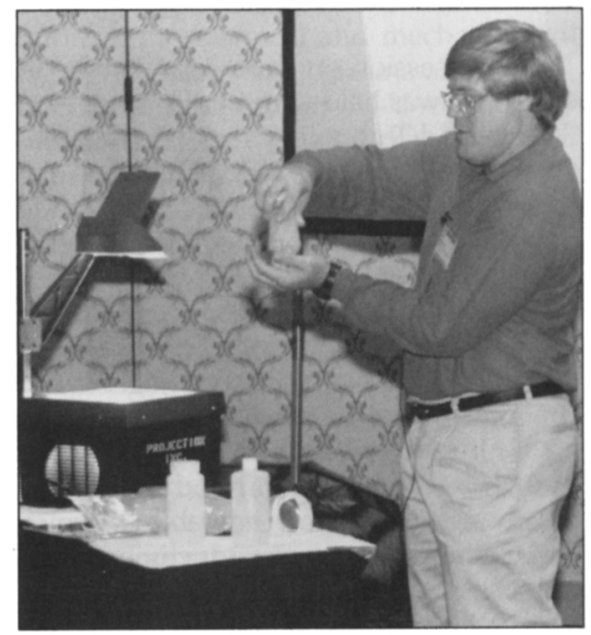

Rob Sorenson makes "slime" in the Grass Roots Education Session, demonstrating activities that scientists can do in classrooms to inspire interest in science.

presentations. Fracture behavior in intermetallics was discussed by J. R. Rice of Harvard and $\mathrm{H}$. Vehoff of the Max-PlanckInstitut. M. Yamaguchi of Kyoto University presented some early work on the deformation behavior of single-crystal cobalt silicides. The application of $\mathrm{NiAl}$ as a material for turbine blades was discussed by D. LaChapelle of General Electric Aircraft Engines. An excellent review of the recent progress in $\mathrm{Ti}_{3} \mathrm{Al}$ was presented by H. A. Lipsitt of Wright State University. P. B. Hirsch, University of Oxford, also gave a Symposium $X$ tutorial on ductility issues in intermetallics. 


\section{Short-Range Interparticle Forces Control Dense Suspension Microstructure and Flow Characteristics}

(See MRS Proceedings Vol. 289)

Symposium M, Flow and Microstructure of Dense Suspensions, addressed recent advances in rheological characterization techniques and was a forum to develop links between investigations of model suspensions and more complex systems of technological importance.

A dominant topic was the role of shortrange interparticle forces in controlling dense suspension microstructure and flow characteristics. This subject was emphasized in papers dealing with friction between molecularly smooth surfaces coated with surfactants or polymer layers where links between adhesion and friction were explored. Major conclusions were that friction is related to the contact surface energy and the rate of loading, while polymer layers were shown to provide low-friction surfaces. Applications of these concepts were illustrated in studies of processing dense flocculated suspensions where floc rearrangement under shear and compressive loads was clearly linked to the strength of the attractive potential, which could be manipulated through short-range repulsive potentials of steric, solvation, or hydration origin. In addition, simulations of aggregated suspensions under shear flow showed that under conditions where interparticle bonds are not rigid and hydrodynamics is treated in the Stokes drag limit, shear tends to densify open networks. It is not until the suspension is deformed, when large shear rates are applied, that the flocs are disrupted into single particles.

The second theme developed throughout the symposium was related to shear effects on suspension microstructure and links between microstructure and flow behavior. Shear thickening in hard-sphere and change-stabilized suspensions was clearly associated with the development of large aggregates that, for some particle interaction potentials, were reversibly degraded when the shear rate was reduced. In hard-sphere suspensions, the critical shear rate of the onset of thickening was found to scale as (particle size) ${ }^{2}$, while in charge-stabilized suspensions, the critical stress was found to scale on the elastic modules. The significance of understanding shear thickening phenomena was further emphasized in studies showing that technological advances revolve around processing increasingly dense suspensions where shear-thickening occurs at ever smaller deformation rates.

A third theme permeating the symposium was understanding particle migra- tion under shear and extensional flow. Discussion of the movement of large particles $(\sigma>5 \mu \mathrm{m})$ out of a region of high shear and the development of slip layers at the suspension (paste)/rheometer tool interface illustrated the continuing need to develop an understanding of suspension dynamics under complex flow conditions. Difficulties in formulating constitutive relationships for dense suspensions were further emphasized in a series of presentations on cement and concrete rheology, where characterizing the flow of an agglomerated material is further complicated by chemical reactions that alter particle size distribution, interaction potential, and volume fraction.

Finally, a wide range of structure determination techniques was illuśtrated. Small-angle light scattering and visual observation were discussed as methods to probe the crystallization of shear melted, hard-sphere suspensions and structure formation (and dynamics) in suspensions containing particles with external fieldinduced dipoles. Results from NMR imaging, x-ray tomography, small-angle neutron scattering, and birefrigence measurements were discussed as methods for following microstructural evolution under shear and densification.

The increasingly sophisticated understanding of particle interactions and dense suspension mechanics discussed in the symposium found immediate ramifications in process technologies, while the challenges in developing design rules with a fundamental origin were clearly evident from presentations on the complex phenomena with which technologists struggle on a day-to-day basis.

\section{Dynamics in}

\section{Small Confining Systems}

Symposium N, on Dynamics in Small Confining Systems, displayed a broad spectrum of problems and approaches related to systems confined in space by the presence of boundaries. The organizersJ.M. Drake of Exxon, J. Klafter of Tel Aviv University, R. Kopelman of the University of Michigan, and D.D. Awschalom of Santa Barbara-brought together chemists, physicists and chemical engineers. These scientists are both experimentalists and theorists, who presented new results on structural and dynamic properties of molecular systems at interfaces.

The symposium was organized around the following sessions: Structure and Dynamics of Polymers at Interfaces, Dynamics and Thermodynamics of Confined Gases and Liquids, Flow and Relaxation in Porous Media (joint session with symposium $P$ ), and a special session (in memory of the late Lola Anacker) on Diffusion and Reactions in Confined Systems. Presentations touched upon issues of adsorption, wetting, phase-separation, freezing and melting, diffusion and reactions, all in restricted geometrics.

The topics discussed in the symposium covered recent studies on viscosity changes and slipping transitions in polymers at solid interfaces; adsorption of and wetting by polymers; critical binary fluids in porous media; molecular dynamics simulations of shear flows in thin confined films, of the spreading of liquid drops, and of gas adsorption; NMR and optical probes as tools to follow the structure and dynamics in confined systems; and reaction models of surface catalysis.

\section{Modeling, Theory, and Technique Excelled by Expanding Computer Power \\ (See MRS Proceedings Vol. 291)}

Advances in theory and numerical methods, the maturation of modeling techniques, improving accessibility of simulations technology, and the expanding power of workstation and supercomputer hardware are all contributing to continued growth in the interest and application of computational techniques in materials science. The breadth of the impact of modeling was reflected in Symposium $O$, Materials Theory and Modeling, which included the well-attended overview by $G$. $B$. Taggart of those programs supported by the National Science Foundation involving a significant theory or modeling component. Modeling is viewed as the key to several current and planned initiatives.

The symposium presentations ranged from first principles electronic structure calculations to simple applications using geometrical or statistical models. The challenge for the former is for their applicability to be extended to larger systems and to dynamic phenomena. Work on the phase diagram of silica described by J. Chelikowsky of the University of Minnesota, however, illustrated that such methods can already be applied to topical structural issues. First principles calculations are also being used to parameterize interatomic potentials of the embedded atom (EAM) or many body alloy form. The EAM potential that has been applied successfully to large simulations of face-centered cubic metals is now being extended, via the use of angular terms, to body-centered cubic materials. Significant headway in the prediction of alloy phase diagrams, a major technological interest, was discussed. Promising and diverse theoretical approaches are being pursued by several groups. M. S. Daw of Sandia National Laboratories provided a 
new perspective on the density matrix, J. V. Lill, Naval Research Laboratory, outlined rigorous approaches to molecular dynamics, and S. R. Phillpott, Argonne National Laboratory, described the use of variable-occupancy atoms as a route to Grand Canonical Monte Carlo simulations on dense systems. Massively parallel (MP) computer architectures are already extending the size and scope of simulations, and, as highlighted by several researchers, MP architectures typically require a new approach to software structuring

Ionic systems were the topic of several presentations. P. Vashishta of Louisiana State University summarized an extensive series of simulations on silica, spanning a density range from that observed at 40 Mbar, when silica is in the 6-coordinate stishovite phase, down to that of the intraparticle density appropriate for fused silicas. Structural and ordering characteristics of oxide superconductors were discussed and, complementing the content of Symposium AA, different aspects of the structure, bonding, and properties of fullerenes and related carbon cages and tubules were addressed in several talks.

\section{Mode Coupling Theory for Glass Transition Supported by Light-Scattering Data}

Two talks in the area of slow relaxation (H. Z. Cummins, City University of New York, and K. A. Nelson, MIT) discussed experimental light-scattering data that give strong support to the ideas of mode coupling theory for the glass transition. Further computer simulations by L. J. Lewis, University of Montreal, also reported similar agreement with the theory.

The lively discussion by the audience in Symposium P, Disordered Materials: Fractals, Scaling, and Dynamics, emphasized that the data are in agreement with the theory only at temperatures far above the real glass transition. They seem to explain the viscosity and time scales of the supercooled liquid as it first starts to slow down but do not explain the dramatic increase of these quantities as they seemingly diverge nearer to the glass transition. It was also pointed out that the mode coupling appears to account for the higher frequency relaxation phenomena that was once believed to be the same as the $\beta$ or secondary relaxation. The current evidence is that this relaxation is not what had been earlier measured by susceptibility probes.

The talk by N. O. Birge of Michigan State University on $1 / f$ noise in metals showed that this phenomenon could be understood at low temperatures in terms of a distribution of time scales that occur for impurity atoms tunneling between two wells. The large enhancement of the noise at low temperatures, though initially surprising, could be understood from models based on fluctuation theory. The talk by $P$. G. Wolynes, University of Illinois, reported on attempts to predict the way that proteins fold. This work is based on ideas taken from, among other sources, spinglass theory.

There was a lot of discussion concerning the causes and patterns of convection in granular materials induced by vibration. It became apparent that the boundary conditions, especially the slip conditions at the walls, determined much of the nature of the flow patterns. G. Grinstein of the IBM T. J. Watson Research Center emphasized the importance of different time scales as a way of distinguishing self-organized critical behavior from the more common generic scale invariance. T. Hwa, Harvard University, and C. Tang, NEC Research Institute, discussed the scale invariance that appears in different types of avalanche dynamics such as in the pinned flux motion in superconductors and the motion of polymers in random media.

The talks on spatial organization in nonequilibrium processes were both stimulating and visually appealing, many using videos. The presentation by $\mathrm{H}$. $\mathrm{H}$. Rotermund, Fritz-Haber Institut der MPG, discussed new experimental imaging techniques for monitoring the surface composition during the oxidation of $\mathrm{CO}$ on $\mathrm{Pt}$ surfaces. This reaction exhibits beautiful spatial patterns, including spiral waves, solitons, and other more unusual structures. R. M. Ziff, University of Michigan, discussed a simple microscopic model that reproduces many of the experimental observations. Talks by A. Karma, Northeastern University, and J. N. Chazalviel, Ecole Polytechnique, Palasiseau, France, discussed pattern formation in the presence of driving forces. The latter talk indicated that hydrodynamic effects play a strong role in determining the ensuing morphology. The talk by P. De Kepper, University of Bordeaux I, showed perhaps the best examples of Turing patterns under controlled experimental conditions. H. Levine, UCSan Diego, gave a theoretical overview of spiral wave propagation in excitable media, with useful implications for the experimental results given by Rotermund. Finally, J. E. Martin of Sandia National Laboratories discussed the rheology of fluids in which particulate suspensions form $\mathrm{CO}-$ lumnar structures in the presence of electric fields. In addition to yielding interesting spatial patterns, this system exhibits a rich variety of hydrodynamic effects.

In the session on morphology of non- equilibrium growth processes, T. C. Halsey of the University of Chicago gave an elegant theoretical discussion of a minimal model in which competition between bifurcating branches is the essential mechanism that leads to multifractality in diffusion-limited growth. R. Du of Harvard University discussed the complex structures formed by evaporative growth.

A. J. Dougherty of Lafayette College treated the shape of dendrites in three dimensions. In contrast, much previous work has been restricted to twodimensional images. P. G. Felton, Prince ton University, presented experimental work on the imaging of internal combustion engine flames, drawing lively discussion. The data show that the flame front is fractal, and this feature can be used as a useful diagnostic of the efficiency of the combustion process. J. Krug, IBM T. J. Watson Research Center, gave a theoretical treatment of ballistic growth processes in that the incident flux is either oblique to the surface or distributed over a range of angles. For each of these two cases, surface morphologies arise that are considerably different from the classical models. The presentation by W. M. Tong, UCLA, offered beautiful images of a growing surface by an atomic-force microscope. This experimental study suggested a number of shortcomings in standard theoretical models of ballistically-driven surface growth. The talks by M. Plischke, Simon Fraser University, and A.-L. Barabasi, Boston University, examined how the scaling properties of a growing surface are influenced by surface diffusion and by coupling between two growing surfaces.

The session on geo- and micromechanics attempted to pull together recent overlapping interests in the modeling of earthquakes and crack formation/ propagation in brittle solids. J. P. Gollub of Haverford College used a small laboratory experiment, with an elastic membrane stretched over a glass rod, to mimic the stick-slip friction dynamics built into theoretical models of earthquake dynamics. He was able to demonstrate the large range of spatial scales that are characteristic of the simulations. M. Sahimi, HLRZ Supercomputer Center, presented intriguing experimental data that suggested the use of the percolation theory for the spatial distribution of earthquakes. G. Cody of Exxon Research and Engineering brought considerable insight into a key fixture of modern physics, wave localization in a disordered system, from a system device derived from the mechanical vibration of structural steel parts of a refinery. M. Marder, University of Texas, presented a fascinating talk on an unsolved problem in the fracture dynamics 
of brittle amorphous solids, such as glass or Plexiglas. The problem is the relatively slow (and oscillatory) speed of propagation of the cracks. Work is still in progress to resolve this problem and one useful model candidate is dynamic cracks on discrete lattices.

The session on flow/relaxation in porous media covered a full range of fluidsin-porous-media phenomena. D. $H$. Rothman, MIT, delivered an excellent pedagogic talk on the use of a lattice-gas calculational approach to complex flows in two-dimensional random models. The results agree generally with Darcey law flow predictions. The deviations are due to disconnected flows or high capillary number. M. Blunt, Stanford University, addressed the effect of wettability on capillary dominated flows. In particular, he showed the robustness of scaling laws in predicting the perturbative effects of viscous and gravity forces. W. I. Goldburg, University of Pittsburgh, discussed his latest experimental results on ubiquitous slow $\mathrm{dy}$ namics in phase separation (of nematics) in silica gels. He sees evidence of the freezing of concentration fluctuations.

\section{Synthesis of New Materials Seen as Technique to Understand Polymer Blends}

Several active research areas were brought together in Symposium Q, Polymer Blends. One of the important themes was understanding polymer blends through the synthesis of new materials. This topic was presented in the work of $M$. Galvin of Bell Labs in her studies of the effect of polymer architecture on blend miscibility. Work was also presented on new and important glass-polymer composites.

The interface between phase-separated polymers is a topic of considerable interest. The strategies for preparing blends of controlled structures was presented by $D$. Pearson of UC-Santa Barbara. The characterization of the mobility of polymers at interfaces was studied, using the latest techniques by $S$. Granick of the University of Illinois and P. Pincus of UC-Santa Barbara.

One of the emerging areas in polymer blends is the molecular-level characterization of intermolecular interactions. This was studied using nuclear magnetic resonance spectroscopy by $P$. Inglefield of Clark University and J. Kornfield of the California Institute of Technology, and by $\mathrm{S}$. Hsu of the University of Massachusetts, using atomistic computer simulations. A greater understanding for predicting the structure of polymer blends was the topic of a theoretical talk by M. Muthukumar of

the University of Massachusetts.

\section{Self-Assembled Monolayers to Support AIDS Antigen \\ Fragment-Antibody Complexes Described}

Several new trends in materials chemistry and applications that are not yet apparent from the literature were highlighted in Symposium R, Ordered Materials by Design, a new MRS symposium. One new development is the use of thin films and clusters for inclusion and sensing. C. Sukenik, Case Western Reserve University, described self-assembled monolayers to support AIDS antigen fragment-antibody complexes as a route toward AIDS virus testing. T. Bein of Purdue University employed silane coupling layers as adhesives to fix chemically sensitive zeolite particles to electronically or acoustically sensitive surfaces. Norman Herron, E.I. duPont de Nemours \& Company, has prepared crystalline, porous semiconductor cluster assemblies whose photophysics would be altered by chemical inclusion.

New progress was also revealed in the area of ordered conductive polymers. C. R. Martin of Colorado State University talked about polypyrrole tubules whose shape and interchain packing were determined by the surfaces of membrane pores. The most ordered phases were the most conductive. M. Rubner of MIT described an extremely simple and effective route to organic semiconductor heterostructures consisting of stacked ultrathin films of contrasting polymers. An extremely exciting area of interest is polyphenylenevinylene electroluminescence. A. B. Holmes of the University of Cambridge discussed processes leading to better ordered materials. He converts his precursor polymers to the active form in stages, annealing and ordering segments at each stage. Less quenching of the electroluminescence is observed in the better-ordered samples.

The interplay between organic and inorganic components of composite materials was also highlighted. E. P. Giannelis, Cornell University, has inserted polymers between layers of silicates, thus separating their chains. He has also determined that silicate layers induce ordering of overlying polymers over considerable thicknesses, resulting in greatly reinforced materials. L. Nazar of the University of Waterloo has prepared materials with similar morphologies using molybdenum trioxide and polyphenylene vinylene. T. M. Swager, University of Pennsylvania, presented his new approach to liquid crystals in which activity (ferroelectricity, for example) resides in transition metal centers while specially designed ligands are responsible for

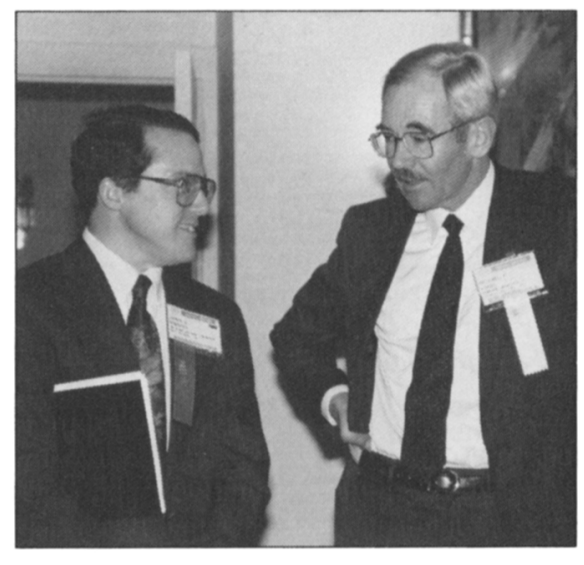

1992 Von Hippel Award winner Michael Ashby (right) chats with Jim Roberto before the awarts ceremony and Von Hippel presentation.

the molecular organization.

The role of hydrogen bonds in crystal engineering was explored in depth. The $\mathrm{G}$. M. Whitesides research group at Harvard enumerated the variety of crystal morphologies induced by the judicious substitution of hydrogen bonding groups in organic molecular components. At a more fundamental and potentially farther-reaching level, M. Lahav of the Weizmann Institute of Science demonstrated how the precise hydrogen bonding arrangement at a liquid-liquid interface can determine the crystal structure and energetics of the interfacial materials as they freeze. Although his specific application was the seeding of clouds to form ice, the same principles determine the progress of many other aqueous and nonaqueous crystallizations.

Other topics covered included surface nonlinear optical materials, catalysts, and organized block copolymers.

\section{Genetic Engineering Seen as Path for Synthesis of Proteins with Potential as Biomolecular Materials (See MRS Proceedings Vol. 292)}

Scientists from numerous disciplines discussed the biology, cellular and noncellular synthesis, structural and mechanical properties, and medical/industrial applications of biological materials. The objects of their studies were presented in Symposium S, Biomolecular Materials, and were as varied as silks, nuts, and shells.

One apparent theme was that materials science provides methods applicable to the study of the ordered structure and mechanical properties of biological polymers. Pure and composite polymers composed of inorganic, organic, and/or biochemical (nucleic acid, protein, polysaccharide, 


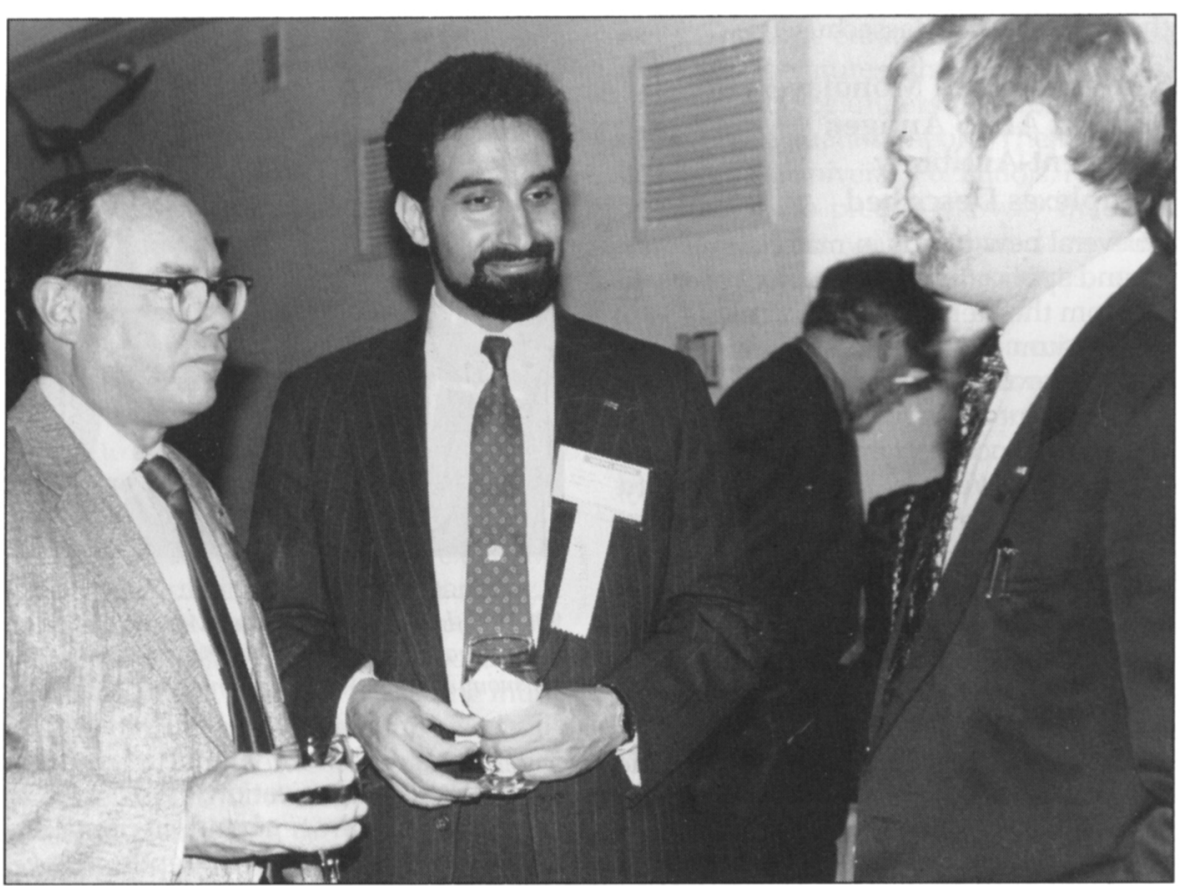

Gordon Pike, Daryush Ila, and Ian Boyd discuss the 1992 Fall Meeting program.

lipid) constituents are often amenable to study. In some instances, the measured properties merit duplication; in others, they provide an origin for novel modifications. Moreover, molecular interfaces in composite polymers may provide regulable sites for innovative materials synthesis.

Another vital theme was that genetic engineering has led to superb progress in the synthesis and biophysical characterization of proteins with potential applications as biomolecular materials. Besides large-scale production of normal proteins, the synthesis of mutant proteins, isolated domains, hybrid molecules and designer peptides can now be achieved. Some of these products mimic the properties of their biological precursor; others are unique. Some provide templates upon which additional processes (such as biomineralization) can be regulated. Current applications of genetically engineered proteins range from cell-specific targeting of molecules for drug delivery to biocompatible peptides that prevent post-operative surgical adhesions.

\section{New Advances Achieved in Rechargeable Lithium Battery \\ (See MRS Proceedings Vol. 293)}

Presentations at Symposium U, Solid State Ionics, included key issues on insertion materials; ionic and electronically conductive polymers; theory of ion transport in solids; application of solid-state ionic materials in devices such as batteries, fuel cells, sensors, and electrochromic devices; and the application of mixed conductors for catalysis. Many innovative in-situ and $e x$-situ techniques for characterization of technological materials were presented.

This symposium witnessed several major contributions to the technological field of ionics. A promising rechargeable lithium battery based on the rocking chair concept was presented. This device is based on a lithiated spinel $\mathrm{Mn}_{2} \mathrm{O}_{4}$ cathode and graphitized carbon as the anode of the cell. Long cycle life and high energy and power density were shown. In the field of solid electrolytes, C. A. Angell from Arizona State University presented a new class of electrolytes with high ionic conductivity. The new electrolyte is based on a molten salt-polymer system. His approach is unique because the system takes advantage of the high conductivity of roomtemperature molten salt and the rubbery phase of polymer, which provide fast ion motion and mechanical flexibility for solid electrolytes. F. K. Shokoohi of Bellcore presented microfabrication of batteries on chips, providing a new possibility in the architecture of advanced electronics. This is especially important in the design of biosensors in which the size of the device is an important factor. The other important technological innovation was presented by J. Livage, University of Paris VI: a review of new possibilities using the sol-gel process. Fabrication of large-scale, multilayer microionic devices and coatings was presented. He also showed that by controlling the solgel process, a variety of new multicomponent ceramics and glasses with desired properties can be made. Many fundamental issues of the structure-property relationship in mixed conductors and polymeric electrolytes and electrodes were also discussed.

\section{Performance of Engineered and Geological Systems for Nuclear Waste Storage Debated by Panel (See MRS Proceedings Vol. 294)}

Symposium V, Scientific Basis for $\mathrm{Nu}$ clear Waste Management XVI, covered a wide range of topics related to the scientific basis for solutions to technical problems in nuclear waste management. Presentations were given on a variety of topics: low-level waste, especially cementitious materials; the waste form and its characteristics, e.g., spent fuel, glass (leaching mechanisms); understanding transport behavior, both nearby and at considerable distances from the waste form; and performance of engineered and geological systems. A panel of experts fielded questions from a receptive audience on this last topic, which is not usually covered in this series.

In the field of high-level waste, periods of 1,000 to 100,000 years were discussed, and it was recognized that in making predictions for repository service life, materials behavior cannot be simply extrapolated from short-term data. The critical role of science in the development of acceptable solutions to some of the materials problems was the focus of papers presented in a session on long-term predictions. Arguments on the important role of good engineered practices and their limitations were developed. Long-term predictions must be tempered by knowledge of the limits of scientific understanding and the possibility that a myriad of environmental conditions may exist over the life of a repository. Attempts to deal with these uncertainties can bring imaginative solutions to mind. One author suggested looking more closely at plasters that are over 2,000 years old and have endured since the Hellenic Age. Another author related current predictions to probabilistic understandings based on examinations of pipelines with a service life of much much less than 100 years.

One most important aspect for this particular symposium is that it deals with the scientific basis for management of nuclear waste. Authors were encouraged to stress the science, to specify areas in which their 
work furthers better scientific understanding, to delineate areas of scientific (or engineering) uncertainty, and to describe how their work promotes the understanding needed for management of nuclear waste. Due to the interdisciplinary character of nuclear waste problems, authors were asked to attempt, where possible, to show how their work fits into the overall scheme of nuclear waste management. Responding to these challenges, the authors presented examples of how science can be used to improve the nuclear waste situation: characterizations and analyses of the structure and properties of materials in relation to materials performance over long periods; questions and points of uncertainty in the application of materials to specific waste management problems, such as the migration of grain boundaries or the possibilities for microbial action; and solutions to materials processing problems.

In addition to the materials problems, this symposium addressed various nearfield and far-field topics on hydrology, geochemistry, and geohydrology.

\section{High Tech and High Resolution Draw Imagination and Image Closer Together}

(See MRS Proceedings Vol. 295)

The gap between imagining and imaging is getting ever smaller. Symposium W, Atomic Scale Imaging of Surfaces and Interfaces, brought together researchers using most state-of-the-art imaging techniques capable of resolving atomic features. Methods represented were scanning tunneling microscopy (STM), atomic force microscopy (AFM), low energy electron microscopy (LEEM), transmission (TEM) and reflection (REM) electron microscopy, scanning electron microscopy (SEM), atom probe field ion microscopy (APFIM or POSAP), high- and low-energy external source electron holographies, and internal source electron holographies. Some highlights from the STM papers included discussions of the limitations and future potential of STM as well as current findings. Several papers presented work with STM at elevated temperatures. J. A. Golovchenko of Harvard University reviewed STM work showing cooperative diffusion events $(\mathrm{Pb}$ on $\mathrm{Ge}$ ) involving many tens of substrate atoms. D. M. Eigler of the IBM Almaden Research Center focused on atomic manipulation and some of its uses to enable fundamental studies of small atomic clusters. From LEEM studies, R. M. Tromp, IBM T. J. Watson Research Center, showed videos of $\mathrm{Zd}$-faceted $\mathrm{Ag}$ island growth on $\mathrm{Ge}$. In synchronization with the layer-by-layer growth on the islands, a sharpening-rounding transition occurred at the completion-initiation of each layer. Novel TEM work included highly clean and stable in-situ cross-sectional and planview observations of changing surface and interface structure. A series of papers on cross-sectional TEM imaging of interfaces demonstrated great progress in structure refinements using correlations between atomistic simulations and experimental micrographs. Results from REM were reviewed by Y. Tanishiro of the Tokyo Institute of Technology to show the efficacy of this tool for non-invasive use in deposition environments, and T. Hsu, University of Utah, demonstrated its usefulness for characterizing the atomic-scale morphology of oxide surfaces. A. Bourret of AT\&T Bell Laboratories underlined the necessity of applying complementary methods (here TEM and grazing incidence $x$-ray diffraction) for a complete elucidation of more complicated interface structures. M. R. Scheinfein of Arizona State University described experiments clarifying the origin of fast secondary electron emission and indicated that under optimal conditions, nearatomic-scale resolution may be possible in SEM. H. J. Kreuzer of Dalhousie University discussed the state of the art and future of point source electron holographic imaging. Its low energy and lensless configuration promise many exciting possibilities. Several talks showed the usefulness of atom probe FIM for near-atomic-scale $(\sim 1$ $\mathrm{nm}$ ) chemical/structural analysis. Another area of considerable progress is internal source electron holography. Artful removal of multiple scattering effects is allowing experimental phase coherent diffraction data at multiple energies to be transformed back to the spatial domain. The resulting images are chemically specific mappings representing an average site (central atom and near neighbors). Both LEED and photoelectron diffraction methods were treated.

\section{New Symposium Paints Broad Picture of Energetic Materials (See MRS Proceedings Vol. 296)}

The hoped-for blend of experiment, theory, applications, and science was evident in the presentations during Symposium $Y$, Structure and Properties of Energetic Materials, the first on this topic. Topics ranged from new chemical compositions, through ultra-fast spectroscopies, to a new appreciation of microstructure's role and of molecular dynamic modeling. A portrait of the broad range of chemical and physical phenomena associated with energetic materials was drawn. This range is large because compositions of these materials cover both organic and inorganic elements. The dynamics involve time intervals from milliseconds to femtoseconds (12 orders of magnitude), and the combustion conditions include pressures up to multimegabars at kilo-Kelvin temperatures.

Such wide-ranging topics cannot be summarized comprehensively, so only a small selection of topics will be covered.

Since the ancient invention of gunpowder, experimental techniques have been too slow to resolve the critical events of fast chemical reactions in solids. Only recently have spectroscopies penetrated the subpicosecond time-domain that is necessary, and K. M. Nelson of MIT described the state of the art. The products of fast combustion reactions were also described.

Computational physics is of genuine use in this field because it is extremely difficult to reveal mechanisms experimentally. Therefore, interest in the molecular dynamics modeling done by $C$. T. White's group at the Naval Research Laboratory is intense, and a videotape of the model was shown. It showed diatomic molecules reacting at a moving detonation front, confirming that such fronts are very sharp.

In the hands of J. R. Stine of Los Alamos National Laboratory, it has become possible to relate the molecular structures of secondary explosives (composed of $\mathrm{C}, \mathrm{N}, \mathrm{O}$, and $\mathrm{H}$ ) to their performance; a tour de force in the field of data assemblage and analysis.

As a result of the growth of individual energetic crystals by H. H. Cady, Los Alamos National Laboratory, and J. N. Sherwood, University of Strathclyde, it has become clear that fast chemical reactions in the solid state are not an isotropic phenomenon. J. J. Dick of Los Alamos National Laboratory has demonstrated their anisotropic response to shock loading using $\mathrm{Ca}$ dy's crystals.

The reactions in energetic solids are also interesting because their rates are not determined by temperature alone. The direct actions of mechanical shear strains also play a critical role. Mechanisms for this were discussed by several scientists.

New molecular structures for future explosives and propellants were described by $R$. Gilardi of the Naval Research Laboratory. Examples are nitrated cubanes and other strained ring compounds.

Finally, the symposium was privileged to hear C. Zener of Carnegie Mellon University present a theory written by himself and D. C. Prieve explain why droplets striking a nonwetting solid explode into radially directed jets. 


\section{MIRSS 1992 FALL MEETING \\ MATERIALS \\ RESEARCH \\ SOCIETY \\ SYMPOSIUM PROCEEDINGS}

\section{Place your order today for proceedings from the 1992 MRS Fall Meeting in Boston. You'll receive your books as soon as they are published.}

A: Beam-Solid Interactions - Fundamentals and Applications

Editors: M.A. Nastasi, N. Herbots,

L.R. Harriott, R.S. Averback

ISBN: $1-55899-174-3$

Code: $279-\mathrm{B}$

$\$ 58$ MRS Members

\$67 U.S. List

$\$ 77$ Foreign

\section{B: Evolution of Surface and Thin Film}

Microstructure

Editors: H.A. Atwater, E. Chason,

M. Grabow, M. Lagally

ISBN: 1-55899-175-1

Code: $280-B$

$\$ 58$ MRS Members

\$67 U.S. List

$\$ 77$ Foreign

D: Semiconductor Heterostructures for

Photonic and Electronic Applications

Editors: D.C. Houghton, C.W. Tu, R.T. Tung

ISBN: 1-55899-176-X

Code: $281-B$

$\$ 58$ MRS Members

\$67 U.S. List

$\$ 77$ Foreign

E: Chemical Perspectives of Microelectronic

Materials III

Editors: C.R. Abernathy, C.W. Bates,

D.A. Bohling, W.S. Hobson

ISBN: 1-55899-177-8

Code: $282-B$

$\$ 58$ MRS Members

\$67 U.S. List

$\$ 77$ Foreign

\section{F: Microcrystalline Semiconductors -}

Materials Science \& Devices

Editors: Y. Aoyagi, L.T. Canham,

P.M. Fauchet, I. Shimizu, C.C. Tsai

ISBN: 1-55899-178-6 Code: 283-B

$\$ 60$ MRS Members

\$69 U.S. List

$\$ 79$ Foreign

G: Amorphous Insulating Thin Films

Editors: f. Kanicki, R.A.B. Devine,

W.L. Warren, M. Matsumura

ISBN: 1-55899-179-4

Code: 284-B

$\$ 60$ MRS Members

$\$ 69$ U.S. List

$\$ 79$ Foreign
I: Laser Ablation in Materials Processing Fundamentals and Applications

Editors: B. Braren, J. Dubowski, D. Norton

ISBN: 1-55899-180-8 Code: 285-B

$\$ 55$ MRS Members

$\$ 63$ U.S. List

$\$ 72$ Foreign

J: Nanophase and Nanocomposite Materials Editors: S. Komarneni, J.C. Parker,

G.J. Thomas

ISBN: 1-55899-181-6

Code: 286-B

$\$ 55$ MRS Members

$\$ 63$ U.S. List

$\$ 72$ Foreign

K: Silicon Nitride Ceramics - Scientific and Technological Advances

Editors: I-W. Chen, P.F. Becher, M. Mitomo, G. Petzow, T-S. Yen

ISBN: 1-55899-182-4

Code: 287-B

$\$ 55$ MRS Members

\$63 U.S. List

$\$ 72$ Foreign

L: High-Temperature Ordered Intermetallic Alloys V

Editors: I. Baker, J.D. Whittenberger,

R. Darolia, M.H. Yoo

ISBN: 1-55899-183-2

Code: 288-B

$\$ 60$ MRS Members

$\$ 69$ U.S. List

$\$ 79$ Foreign

M: Flow and Microstructure of Dense

Suspensions

Editors: L.J. Struble, C.F. Zukoski, G. Maitland

ISBN: 1-55899-184-0

Code: 289-B

$\$ 60$ MRS Members

\$69 U.S. List

$\$ 79$ Foreign

N: Dynamics in Small Confining Systems

Editors: J.M. Drake, D.D. Awschalom,

J. Klafter, R. Kopelman

ISBN: 1-55899-185-9

Code: $290-B$

$\$ 60$ MRS Members

\$69 U.S. List

\$79 Foreign
O: Materials Theory and Modelling Editors: P.D. Bristowe, J. Broughton,

J.M. Newsam

ISBN: 1-55899-186-7

Code: 291-B

$\$ 60$ MRS Members

\$69 U.S. List

$\$ 79$ Foreign

S: Biomolecular Materials

Editors: S.T. Case, J.H. Waite, C. Viney

ISBN: 1-55899-187-5

Code: 292-B

$\$ 60$ MRS Members

\$69 U.S. List

$\$ 79$ Foreign

U: Solid State Ionics III

Editors: G-A. Nazri, J-M. Tarascon,

M. Armand

ISBN: 1-55899-188-3

Code: 293-B

$\$ 60$ MRS Members

\$69 U.S. List

$\$ 79$ Foreign

V: Scientific Basis for Nuclear Waste Management XVI

Editors: C.G. Interrante, R.T. Pabalan

ISBN: 1-55899-189-1

Code: 294-B

$\$ 55$ MRS Members

$\$ 63$ U.S. List

$\$ 72$ Foreign

W: Atomic-Scale Imaging of Surfaces and Interfaces

Editors: D.K. Biegelson, D.S.Y. Tong,

D.J. Smith

ISBN: 1-55899-190-5

Code: $295-B$

$\$ 60$ MRS Members

\$69 U.S. List

\$79 Foreign

Y: Structure and Properties of Energetic

Materials

Editors: R.W. Armstrong, J.J. Gilman

ISBN: 1-55899-191-3

Code: 296-B

$\$ 60$ MRS Members

$\$ 69$ U.S. List

$\$ 79$ Foreign

\section{ORDER FROM:}

\section{MATERIALS RESEARCH SOCIETY}

9800 McKnight Road, Pittsburgh, PA 15237, (412) 367-3012; FAX (412) 367-4373.

In Europe, Africa, or the Middle East, contact: Clarke Associates - Europe Ltd.

13a Small Street, Bristol BS11DE, England; Phone: 0272 268864; FAX 027226437 